\title{
Potential Antifungal Targets against a Candida Biofilm Based on an Enzyme in the Arachidonic Acid Cascade-A Review
}

\author{
Xinning Liu ${ }^{1}$, Decai Wang ${ }^{1}$, Cuixiang $\mathrm{Yu}^{2}$, Tao $\mathrm{Li}^{3}$, Jianqiao $\mathrm{Liu}^{4}$ and Shujuan Sun ${ }^{5 *}$ \\ ${ }^{1}$ Department of Clinical Pharmacy, Taishan Medical University, Taian, China, ${ }^{2}$ Respiration Medicine, Qianfoshan Hospital \\ Affiliated to Shandong University, Jinan, China, ${ }^{3}$ Intensive Care Unit, Qianfoshan Hospital Affiliated to Shandong University, \\ Jinnan, China, ${ }^{4}$ General Practice, Shandong Provincial Hospital, Jinnan, China, ${ }^{5}$ Pharmaceutical Department, Qianfoshan \\ Hospital Affiliated to Shandong University, Jinnan, China
}

OPEN ACCESS

Edited by:

Miguel Cacho Teixeira, University of Lisbon, Portugal

Reviewed by: Hans Uwe Dahms, Kaohsiung Medical University, Taiwan

Carolina Henritta Pohl, University of the Free State, South Africa

${ }^{*}$ Correspondence: Shujuan Sun sunshujuan888@163.com

Specialty section:

This article was submitted to Infectious Diseases,

a section of the journal

Frontiers in Microbiology

Received: 22 July 2016 Accepted: 16 November 2016 Published: 06 December 2016

Citation:

Liu X, Wang D, Yu C, Li T, Liu J and Sun S (2016) Potential Antifungal Targets against a Candida Biofilm

Based on an Enzyme in the Arachidonic Acid Cascade-A Review. Front. Microbiol. 7:1925 doi: 10.3389/fmicb.2016.01925
Candida is an important opportunistic fungal pathogen, especially in biofilm associated infections. The formation of a Candida biofilm can decrease Candida sensitivity to antifungal drugs and cause drug resistance. Although many effective antifungal drugs are available, their applications are limited due to their high toxicity and cost. Seeking new antifungal agents that are effective against biofilm-associated infection is an urgent need. Many research efforts are underway, and some progress has been made in this field. It has been shown that the arachidonic acid cascade plays an important role in fungal morphogenesis and pathogenicity. Notably, prostaglandin E2 ( $\left.\mathrm{PGE}_{2}\right)$ can promote the formation of a Candida biofilm. Recently, the inhibition of $P \mathrm{PE}_{2}$ has received much attention. Studies have shown that cyclooxygenase (COX) inhibitors, such as aspirin, ibuprofen, and indomethacin, combined with fluconazole can significantly reduce Candida adhesion and biofilm development and increase fluconazole susceptibility; the MIC of fluconazole can be decrease from 64 to $2 \mu \mathrm{g} / \mathrm{ml}$ when used in combination with ibuprofen. In addition, in vivo studies have also confirmed the antifungal activities of these inhibitors. In this article, we mainly review the relationship between PGE 2 and Candida biofilm, summarize the antifungal activities of COX inhibitors and analyze the possible antifungal activity of microsomal prostaglandin E synthase-1 (MPGES-1) inhibitors; additionally, other factors that influence $\mathrm{PGE}_{2}$ production are also discussed. Hopefully this review can disclose potential antifungal targets based on the arachidonic acid cascade and provide a prevailing strategy to alleviate Candida albicans biofilm formation.

Keywords: Candida albicans, antifungal, arachidonic acid cascade, prostaglandin E2, mPGES-1

\section{INTRODUCTION}

Candida albicans, as a commensal microorganism of the human microbiome and a type of major fungal pathogen, is capable of causing disseminated or chronic infections. These infections often come with high mortality and morbidity in critically ill patients and immunocompromised individuals, such as AIDS patients, patients undergoing anticancer therapies, and so on (CarrilloMuñoz et al., 2006). The National Healthcare Safety Network (NHSN) at the Centers of Diseases 
Control and Prevention (CDC) has reported that Candida spp. ranked fifth among hospital-acquired pathogens (Sievert et al., 2013). Fluconazole is one of the most commonly used antifungal drugs for human candidiasis; however, its extensive use has increased Candida resistance and led to refractory fungal infection (Silva et al., 2012). In addition, C. albicans can easily form a biofilm on the surface of catheters and other medical devices, which is the main cause of biomaterial-related infections. The National Institutes of Health reported that biofilms are responsible for over $80 \%$ of all microbial infections in the United States (Fox and Nobile, 2012). Therefore, identifying efficacious drugs that inhibit biofilm formation is critical to overcome the resistance of $C$. albicans. The arachidonic acid (AA) cascade is essential for mediating human biological activity and plays an important role in fungal morphogenesis and growth. Almost every key enzyme of the AA cascade has been the subject of pharmaceutical research (Meirer et al., 2014). AA is the main precursor of eicosanoids, and AA can be released from membrane phospholipids after catalysis by phospholipases (Dennis et al., 2011) and can be metabolized into many types of biologically active eicosanoids via the action of three separate groups of enzymes: cyclooxygenases, lipoxygenases (LOX), and cytochrome P450 (CYP). Lipoxygenase and cytochrome P450 catalyzes leukotrienes (LT; Peters-Golden and Henderson, 2007) and epoxyeicosatrienoic acids (EET; Spector, 2009), respectively. As the most popular enzyme, COX catalyzes the formation of thromboxane (TX), and prostaglandins (PG; Clària, 2003). $\mathrm{PGE}_{2}$, the most abundant PG, has been previously reported to mediate several biological phenomena, such as homeostasis (Sugimoto et al., 2000), inflammation, pain (Davies et al., 1984), and tumorigenesis (Wang and Dubois, 2010). Recent research has revealed that $\mathrm{PGE}_{2}$ is produced by human eukaryotic cells as well as by pathogenic fungi (Noverr et al., 2001, 2002). AA in combination with antifungal agents can affect $\mathrm{PGE}_{2}$ levels in several Candida species (Mishra et al., 2014). Some studies have suggested that fungal prostaglandin can act as a regulator for biofilm development in C. albicans and that it is also a significant virulence factor in biofilm-associated infections of $C$. albicans (Alem and Douglas, 2005). In this review, we mainly discussed the role of $\mathrm{PGE}_{2}$ in mediating C. albicans biofilm formation and the antifungal activity of the COX inhibitor of the arachidonic acid cascade, as well as other impact factors that influence the formation of $\mathrm{PGE}_{2}$.

\section{$\mathrm{PGE}_{2}$ AND CANDIDA BIOFILM}

The pathogenicity of $C$. albicans includes several virulence factors, such as adhesion, biofilm formation, and phenotypic switching (Calderone and Fonzi, 2001). The proclivity of $C$. albicans to form biofilms has caused a range of superficial mucosal infections and severe disseminated candidiasis (Fox and Nobile, 2012). A variety of urinary and central venous catheters are susceptible to C. albicans biofilm formation, and almost $50 \%$ of these catheters develop a biofilm infection (Nobile and Johnson, 2015). The treatment of catheter-related infections in the clinical setting is a challenge because $C$. albicans biofilm is intrinsically resistant to the host immune system and conventional antifungal drugs (Blankenship and Mitchell, 2006; Nobile and Johnson, 2015). The resistance of C. albicans biofilm cells to antifungal drugs is higher than that of planktonic cells, and the corresponding MICs were 302000 times higher (Douglas, 2003). Therefore, inhibiting biofilm formation is important for fungal resistance reversing. Recent researches show that $\mathrm{PGE}_{2}$ is able to regulate a diversity of host immune responses. It can inhibit Th1-type and promote Th2type immune responses, which are responsible for regulating diverse homeostatic and inflammatory processes (Shibata et al., 2005). And imbalance of the Th response will cause chronic or disseminating fungal infections (Romani and Kaufmann, 1998). C. albicans has been reported to produce $\mathrm{PGE}_{2}$ in $\mathrm{HeLa}$ cells (Deva et al., 2001). Previous study certified that in mammalian cells, fungal $\mathrm{PGE}_{2}$ is able to down-modulate the production of chemokine and TNF- $\alpha$, it exhibits the similar activities as mammalian $\mathrm{PGE}_{2}$, and that both are able to enhance fungal cell adhesion, biofilm development, and germ tube formation in C. albicans (Noverr et al., 2001). $\mathrm{PGE}_{2}$, as the regulator of the dimorphic structure of $C$. albicans, shows ability to increase intracellular cyclic AMP (cAMP) levels and stimulates C. albicans germ tube formation (Kalo-Klein and Witkin, 1990; Douglas, 2003). So enhancing $\mathrm{PGE}_{2}$ level during fungal infections can aggravate fungal colonization in biofilm formation and trigger chronic infection (Noverr et al., 2001). Evidence reveals that candidiasis is associated with high levels of $\mathrm{PGE}_{2}$ (Noverr et al., 2003), and decreased prostaglandin production during C. albican infections is an important factor in relieving chronic infections (Mishra et al., 2014). In addition, research suggests that $\mathrm{PGE}_{2}$ is produced in both C. albicans planktonic and biofilm cells (Ells et al., 2011), while biofilm cells secreted significantly more $\mathrm{PGE}_{2}$ than the planktonic cells when determined according to cell dry weight. This may be one of the mechanisms that explain the high resistance of biofilm cells (Alem and Douglas, 2005). Further study showed that several genes play a role in regulating prostaglandin production in C. albicans. Levitin's work suggests that $\mathrm{PGE}_{2}$ can activate the signal transduction pathway of $C$. albicans by changing its transcriptional profile under yeast growth conditions, it indirectly down-regulate the expression of C. albicans homolog of Ctr1 by activating Tup1p repressor and possibly other transcription factors (Levitin and Whiteway, 2007). According to Erb-Downward's research, fatty acid desaturase homolog (Ole2p) and multicopper oxidase homolog (Fet3p) are necessary enzymes that participate in $\mathrm{PGE}_{2}$ biosynthesis in C. albicans (Erb-Downward and Noverr, 2007), while the role of OLE2 in C. parapsilosis is relatively weaker, it is able to decrease C. parapsilosis virulence, but is dispensable for $\mathrm{PGE}_{2}$ synthesis (Grozer et al., 2015). Furthermore, $\mathrm{PGE}_{2}$ production is a significant virulence factor in biofilm-associated infections of $C$. albicans and non-albicans species (Mishra et al., 2014), the relative lower virulence of $C$. dubliniensis compared to C. albicans may be contributed to its lower $\mathrm{PGE}_{2}$ level (Ells et al., 2011). The role of $\mathrm{PGE}_{2}$ in polymicrobial infection has also been studied. In mixed infections containing Candida and bacterial species, such as dual S. aureus/C. albicans polymicrobial biofilms and C. albicans in mixed infections with 
Pseudomonas aeruginosa, both of the pathogens have a tendency to produce $\mathrm{PGE}_{2}$ (Krause et al., 2015; Fourie et al., 2016) and cause nosocomial infections. $\mathrm{PGE}_{2}$, as the key molecule, could stimulate dual biofilm formation, and affect the dynamics of co-infection.

Above all, although there are multiple speculations of the role of $\mathrm{PGE}_{2}$ in $C$. albicans biofilm development and fungal pathogenesis, however, evidence shows that $\mathrm{PGE}_{2}$ has significant effects on fungal morphogenesis and biofilm development, It is indeed, in response to C. albicans infections, both host and fungal cells are sources of prostaglandins production and the host-derived arachidonic acid may be taken up by fungi for prostaglandin synthesis. On the other hand, the detail mechanism of $\mathrm{PGE}_{2}$ regulating biofilm formation and pathogenicity of fungi is not completely clear. So far, some research has shown that several transcriptional regulators control biofilm development in C. albicans. Among these regulators, the CPH1 and EFG1 genes are required for numerous processes, such as morphogenesis and virulence (García-Sánchez et al., 2004); $B C R 1$ is a downstream gene of the hyphal regulatory network that regulates biofilm formation, and HWP1 is used for biofilm adherence in C. albicans (Li et al., 2015; Nobile and Johnson, 2015). However, whether $\mathrm{PGE}_{2}$ modulates biofilm formation of C. albicans by regulating the expression of these genes is still awaiting support from further experiments.

\section{CYCLOOXYGENASE}

The biosynthesis of PG is catalyzed by several enzymes. First, $\mathrm{AA}$ is mediated by COX-1 or COX -2 to form prostaglandin $\mathrm{G} 2\left(\mathrm{PGG}_{2}\right)$, and then, the same enzyme catalyzes the formation of prostaglandin $\mathrm{H} 2\left(\mathrm{PGH}_{2}\right)$. Finally, $\mathrm{PGE}_{2}$ is enzymatically produced as an end product of the reaction of $\mathrm{PGE}_{2}$ synthase (PGES; Park et al., 2006; Iyer et al., 2009). COX inhibitors include non-steroidal anti-Inflammatory drugs (NSAIDs), such as aspirin, indomethacin, ibuprofen, sodium salicylate, and diclofenac sodium, and these are the most widely used drugs in anti-inflammatory therapy. They are used to treat pain and inflammation in a variety of acute and chronic conditions by inhibiting both COX-1 and/or COX-2. $\mathrm{PGE}_{2}$ is a virulence factor in promoting fungal colonization and chronic infection, using pharmacologic agents which can reduce $\mathrm{PGE}_{2}$ production are therapeutic options for Candida related infection (Nash et al., 2016). It has been reported that in human urothelium, C. albicans can induce COX-2/PGE 2 gene expression through EGFRERK/p38-RSK-CREB-1 pathway (Wang et al., 2016). Notably, recent studies have suggested that COX inhibitors had strong antifungal activity against $C$. albicans by a $\mathrm{PGE}_{2}$-dependent mechanism. It can inhibit fungal prostaglandin synthesis and therefore reduce biofilm development in C. albicans (Alem and Douglas, 2004, 2005; Ghalehnoo et al., 2010; Bink et al., 2012; Rusu et al., 2014). They inhibit the growth of C. albicans in a dose-dependent manner (de Quadros et al., 2011). Among them, indomethacin, a potent COX inhibitor, is most effective against $C$. albicans (MFC $0.11 \mathrm{mmol} / \mathrm{L}$ ), followed by aspirin (MFC $0.22 \mathrm{mmol} / \mathrm{L}$ ) and ibuprofen (MFC $0.44 \mathrm{mmol} / \mathrm{L}$ ), while sodium salicylate isconsiderably less potent (MFC $22 \mathrm{mmol} / \mathrm{L}$ ) than the other tested NSAIDs.

Research has shown that aspirin, one of the oldest and most widely used COX inhibitors, exerts desirable inhibitory effects on growing and mature biofilms $(48 \mathrm{~h})$ of $C$. albicans by inhibiting $\mathrm{PGE}_{2}$ synthesis (Alem and Douglas, 2004). It can significantly reduce biofilm synthesis in fluconazole resistant $C$. albicans clinical isolates at a concentration of $1 \mathrm{mg} / \mathrm{ml}$ and eliminate biofilm formation at a concentration of $5 \mathrm{mg} / \mathrm{ml}$ (Abdelmegeed and Shaaban, 2013). Aspirin also has significant effects on the viability of $C$. albicans biofilm cells. Aspirin-treated cells are incapable of cell division, but still retain some level of metabolic activity (Alem and Douglas, 2004). Currently, combination therapy has become a potential alternative treatment for invasive fungal infections, as it can exhibit improved efficacy, a broader spectrum of activity and fewer side effects (Shrestha et al., 2015). In other experiments, the antifungal ability of amphotericin B combined with aspirin against planktonic cells and biofilm cells of $C$. albicans has been evaluated. The antifungal activity of aspirin is weak in both planktonic and biofilm cells, but when aspirin is combined with amphotericin $\mathrm{B}$, it enhances the antifungal activity of amphotericin B, especially on the biofilm cells. The MIC50 values of amphotericin B and aspirin are, respectively, decreased by up to 32- and 16-fold, based on FIC indices (Zhou et al., 2012). Aspirin alone or in combination with conventional antifungal drugs is also beneficial for the treatment of vulvovaginal candidiasis (Deva et al., 2001). In Ghalehnoo's study, diclofenac sodium was shown to have a strong inhibitory effect on filamentation in C. albicans. To clarify the ability of diclofenac sodium to reduce germ tubes and hyphal formation, a RT-qPCR experiment was used to observe the interference of gene expressions in C. albicans. The results show that the expression of CYR1, EFG1, and RAS1 in the CAMP-EFG1 pathway were repressed by the presence of diclofenac sodium, while CST2O and CPH1 in the MAPK pathway were not, suggesting that diclofenac sodium may be involved in the yeast-hypha transition in C. albicans by disrupting the cAMP-EFG1 pathway (Ghalehnoo et al., 2010). Another study found that combining diclofenac with caspofungin led to a successful reduction of biofilm cells in vitro and in vivo and that the presence of diclofenac enhanced the susceptibility to caspofungin. In a catheter-associated biofilm model in rats, the combination of diclofenac with caspofungin treatment resulted in a $>15$-fold significant reduction in biofilm cells compared to the control treatment, which showed a $>5$-fold reduction (Bink et al., 2012). Yucesoy's experiment suggested that a combination of diclofenac sodium with fluconazole in vitro had a synergistic activity against fluconazole-resistant $C$. albicans strains (Yucesoy et al., 2000; Rainsford, 2007) and the MIC of fluconazole was decreased four-fold when combined with diclofenac sodium. These results are parallel with experiments on clinical isolates of C. albicans from AIDS patients (Scott et al., 1995). Nonsteroidal anti-inflammatory drug flufenamic acid (FFA) alone or in combination with amphotericin B, caspofungin and fluconazole might be effective for the prevention of C. albicans biofilms (Chavez-Dozal et al., 2014). Ibuprofen, a NSAID, is crucial for the reversion of azole resistance in C. albicans. 
In a murine model of systemic infection, the combination of ibuprofen, and fluconazole can potentiate the antifungal activity of fluconazole by decreasing the MIC of fluconazole from 64 to $2 \mu \mathrm{g} / \mathrm{ml}$ and reduce the fungal burden and morbidity in fluconazole resistant strains (Pina-Vaz et al., 2000; Arai et al., 2005; Costa-de-Oliveira et al., 2015). As a potential Cdrp blocker, ibuprofen can directly damage C. albicans cell membranes, but the molecular mechanisms of ibuprofen against $C$. albicans are still being uncovered (Ricardo et al., 2009; de Quadros et al., 2011). Anidulafungin (ANF) is an antifungal drug that can inhibit the formation of both planktonic and biofilms cells in C. albicans. In vitro, when aspirin, ibuprofen, and diclofenac are combined with ANF, they show different sensitivity regarding decreasing biofilm formation in several Candida spp. The combination of ANF with NSAIDs has a strong effect on both C. albicans and C. glabrata biofilm production, while the synergistic effect of the combination is weak against C. Guilliermondi (Rosato et al., 2016). The in vitro interactions between aspirin, ibuprofen, and diclofenac sodium with commonly used azoles also have potential effects against planktonic and biofilm cells of T. asahii (Yang et al., 2016).

\section{MICROSOMAL PROSTAGLANDIN E SYNTHASE-1(MPGES-1)}

PGES enzymes, which lie downstream of COXs, have been formed into several isoforms. Current evidence suggests that cytosolic PGES (cPGES) and microsomal prostaglandin E synthase-2 (mPGES-2) are constitutively expressed in cells and are coupled with COX-1 and COX-1/-2, respectively (Murakami et al., 2003). Microsomal PGES-1 (MPGES-1) is stimulus inducible and specifically couples with COX-2; it is the terminal enzyme in the biosynthesis of $\mathrm{PGE}_{2}$ and, ideally, does not affect the formation of other housekeeping PGs (Koeberle et al., 2010; Chandrasekhar et al., 2016). In Chandrasekhar's research, mPGES-1 exhibits selective inhibition of $\mathrm{PGE}_{2}$ in human epithelial cells, carcinoma cells (A549) and human whole blood treated with lip polysaccharides (LPS; Chandrasekhar et al., 2016). An mPGES-1 knock-out experiment shows that mPGES1 deficient mice cannot induce the expression of mPGES-1 in response to LPS (Uematsu et al., 2002; Trebino et al., 2003). In various mice and rat inflammation models, mPGES-1 plays a pathogenic role in tumorigenesis (Fahmi, 2004), inflammation (Trebino et al., 2003; Iyer et al., 2009), and bone metabolism (Saha et al., 2005). An mPGES-1 inhibitor was found to be efficacious for arthralgia (Chandrasekhar et al., 2016) and is regarded as a promising influenza therapeutic target because of its ability to suppress the induction of pro-inflammatory genes (Park et al., 2016). In addition, mPGES-1 participated in various pathophysiological states in which both COX-1 and COX-2 are involved, implying that the role of the mPGES-1 enzyme is partially similar to that of COX (Murakami et al., 2002, 2003; Tanioka et al., 2003).

Non-selective COX inhibitors can result in many adverse effects, such as gastrointestinal complications and renal toxicity, mainly because COX inhibitors disturb the balance of anti-thrombotic prostacyclins $\left(\mathrm{PGI}_{2}\right)$ and pro-thrombotic thromboxane A2 ( $\mathrm{TXA}_{2}$ ) production (Bresalier et al., 2005). Though selective COX-2 inhibitors (coxibs) have an improved gastrointestinal tolerance, clinical studies have shown that COX-2 inhibitors lead to a small but significant increase in cardiovascular risk, which caused rofecoxib and valdecoxib to be withdrawn from the market (Buttgereit et al., 2001; Sun et al., 2007). MPGES-1, the terminal enzyme, is functionally linked to both COX-1 and COX-2 and can produce $\mathrm{PGE}_{2}$ with fewer side effects, and it can also maintain the $\mathrm{TXA}_{2}$ and $\mathrm{PGI}_{2}$ balance (Vidal et al., 2007) without influencing the 12-LOX and 15-LOX pathways (Martel-Pelletier et al., 2003). Currently, mPGES-1 inhibitors are emerging as the foremost agents in the treatment of inflammatory related diseases, but their antifungal activity is still not clear. Therefore, shifting focus to the use of more selective mPGES-1 inhibitors on the anti-fungal front as an alternative pharmacological approach may be a wise treatment strategy (Rådmark and Samuelsson, 2010). Several compounds, including MF-63, Triclosan and many natural products, are considered to be mPGES-1 inhibitors, such as Myrtucommulone from myrtle (Koeberle et al., 2009a), Arzanol from Helichrysum (Bauer et al., 2011), and Curcumin, which have anti-inflammatory and anti-carcinogenic properties (Koeberle et al., 2009b). These natural compounds can efficiently suppress mPGES-1 activity $(\mathrm{IC50}=0.3-10 \mu \mathrm{M})$ and reduce $\mathrm{PGE}_{2}$ levels (Korotkova and Jakobsson, 2014). In addition, licofelone as an mPGES-1 inhibitor has succeeded in reaching the required criteria in phase III clinical trials for treating osteoarthritis (Payandemehr et al., 2015). Pharmacodynamic studies in various animal models have confirmed the effectiveness of licofelone in many types of diseases, such as anti-asthmatic and anticonvulsant effects (Rotondo et al., 2002; Kulkarni and Singh, 2007; Payandemehr et al., 2015). Furthermore, licofelone was also identified as a class of dual mPGES-1/LOX inhibitors, and its ability to block both the mPGES-1 and 5-LOX pathways is considered superior to single interference.

\section{5-LIPOXYGENASE}

The lipoxygenase pathway in human beings mainly consists of three enzymes, 5-, 12-, and 15-lipoxygenase (LOX). 5LOX as a crucial enzyme in the arachidonic acid cascade can mediate 5-OH-eicosatetraenoic acid (5-HETE) and leucotrienes production with the assistance of 5-LO activating protein (FLAP). The human 5-LOX pathway is important for allergic diseases and inflammatory disorders (Murakami et al., 2002; Werz and Steinhilber, 2006). In the research of Mariana MoratoMarques, LTs and the 5-LO signaling pathway were shown to promote NADPH oxidase activation and ROI generation as well as enhance alveolar macrophage anti-fungal activity against C. albicans. The 5-LO-derived leukotrienes (LTs) secreted by alveolar macrophages (AMs) can eliminate C. albicans from the lungs (Morato-Marques et al., 2011). The general LOX inhibitor nordihydroguaiaretic acid (NDGA) does not inhibit PG production in mammalian systems; however, in Candida, NDGA demonstrated effective activity toward inhibition of $\mathrm{PGE}_{2}$ production in whole cells in a dose-dependent manner (ErbDownward and Noverr, 2007). On the other hand, LOX inhibitor shows ability to block the production of PG by inhibiting PLA2 
translocation to cellular membranes, and therefore interfering the level of AA release (Rossi et al., 2010; He et al., 2012). These evidences demonstrated that 5-LO can serve as a regulator of Candida infection, but the certain way of 5-lipoxygenase regulate Candida is not sure.

\section{GROUP IVA CYTOSOLIC PHOSPHOLIPASE A2 (CPLA2 $\alpha$ )}

Cytosolic phospholipase A2 $\alpha$ (cPLA2 $\alpha$ ) enzymes from membrane glycerophospholipids play a central role in regulating arachidonic acid release and PGs synthesis. The activity of CPLA $2 \alpha$ is regulated by intracellular calcium mobilization and phosphorylation by mitogen-activated protein kinases (MAPKs). CPLA $2 \alpha$ triggers PGE $_{2}$ biosynthesis through COX-1 and can induce expression of Il10, Ptgs2, and Nr4a2, while suppressing Tnfa expression in MAPK by increasing cAMP (Yun et al.,
2016). Other results suggest that in the Golgi apparatus, cPLA2, COX-2 and mPGES-1 can provide a beneficial system for $\mathrm{PGE}_{2}$ formation (Evans and Leslie, 2004; Yuan and Smith, 2015). In a cPLA2 $\alpha$ knockout mouse experiment, the cPLA2 $\alpha$-deficient mice appeared to be severely arthritic, implying that $\mathrm{CPLA} 2 \alpha$ is a key player in the pathogenesis of collagen (Hegen et al., 2003). The CPLA2 $\alpha$ inhibitor arachidonyl trifluoromethyl ketone (ATK) plays an important role in ameliorating tissue injury and pain (Khan et al., 2015). The host cPLA2 $\alpha$ can enhance $P$. aeruginosa-induced mouse mortality by mediating the 15LOX and COX-2 signaling pathways (Guillemot et al., 2014). In short-term infection of $C$. albicans, macrophages activate cPLA2 $\alpha$ to preferentially initiate arachidonic acid release for eicosanoid production, and CPLA $\alpha$ is mediated by the b-Glucan Receptor Dectin-1, which can promote C. albicans to stimulate CPLA $\alpha$ release of AA and contribute to generating the signals to activate cPLA2 $\alpha$ (Suram et al., 2006; Parti et al., 2010). In brief, C. albicans engage with multiple receptors on macrophages to

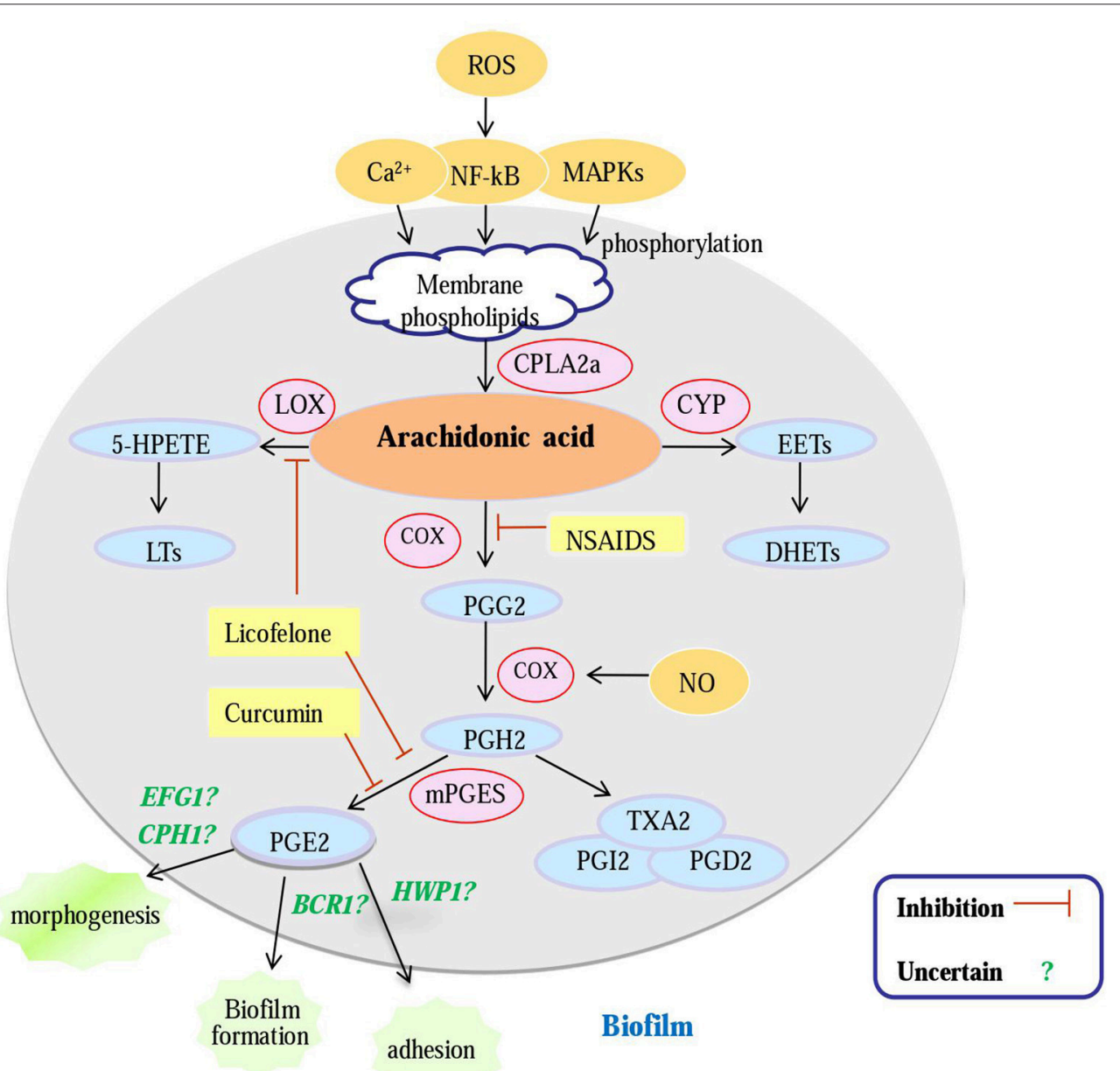

FIGURE 1 | An overview of potential antifungal targets against a Candida biofilm based on an enzyme in the arachidonic acid cascade. Gene (green); enzyme (pink); metabolites (blue); inhibitors (yellow); Question mark: PG E2 can regulate biofilm morphogenesis, biofilm formation and biofilm adherence, whether PGE2 modulates biofilm formation of $C$. albicans by regulating these genes is uncertain; CPLA2a, cytosolic PLA2a; CYP, cytochrome P450; LOX, lipoxygenase; COX, cyclooxygenase; mPGES, microsomal; prostaglandin E2 synthase; NSAIDS, Non-Steroidal Antiinflammatory Drugs; PGG2, prostaglandin G2; PGH2, prostaglandin H2; PGE2, prostaglandin E2; NO, nitric oxide. 
provide signals to activate cPLA2 $\alpha$ and produce eicosanoids, which are keys for modulating inflammation and fungal-related disease (Suram et al., 2010). Therefore, inhibiting cPLA2 $\alpha$ may be a solution to treat $C$. albicans infection by reducing $\mathrm{PGE}_{2}$ production.

\section{OTHERS}

Except for the enzymes discussed above, there are many other factors that regulate enzyme activity and $\mathrm{PGE}_{2}$ biosynthesis. Under hypoxia, intricate temperature- $\mathrm{CO} 2$ modulation is able to reduce hyphal formation of $C$. albicans and influence fungal virulence ( $\mathrm{Lu}$ et al., 2013; Desai et al., 2015). This may be because $\mathrm{PGE}_{2}$ production was decreased while prostacyclin and thromboxane production were increased in hypoxia (Blumenstein et al., 2001). When ROS or ROS-generating xenobiotics are present at low levels, they can activate the prostanoid synthesis pathway and simultaneously activate cPLA2, COX2, and mPGES-1 (Korbecki et al., 2013). Marnett showed that in a model of NOS deficient mice, $\mathrm{PGE}_{2}$ production in macrophages was significantly reduced and that in urine, the level of $\mathrm{PGE}_{2}$ in the NOS deficient groups was decreased by $78 \%$ compared to the control groups (Marnett et al., 2000). In Devaux's study, the results suggest that NOS2-derived NO can activate the mPGES-1 pathway when COX-2 protein expression is absent and that inhibiting the activity of NOS2 decreases the concentrations of $\mathrm{PGE}_{2}$ induced by LPS (Devaux et al., 2001). Hence, NOS2 inhibitors are useful to inhibit the production of $\mathrm{PGE}_{2}$ via COX-2-independent mechanisms. Hemeoxygenases (HOs) have been shown to regulate the levels of eicosanoids derived in the cyclooxygenase, lipoxygenase, and cytochrome $\mathrm{P} 450$ monooxygenase (CYP) pathways. Up regulation of $\mathrm{HO}-1$ or increased $\mathrm{HO}$ activity can suppress $\mathrm{PGE}_{2}$, inducing production of 15-hydroxyeicosatetraenoic acid (HETE), lipoxins, and resolvins (Abraham and Kappas, 2008; Fox et al., 2013). In mammalian cells, sciadonic acid cannot be directly metabolized to $\mathrm{PGE}_{2}$, but it can compete with AA for incorporation into phospholipids and lead to a reduction in $\mathrm{PGE}_{2}$ production (Ells et al., 2012). Several factors influencing $\mathrm{PGE}_{2}$ production were summarized and evidence showed that they also impact the growth of Candida.

\section{CONCLUSION}

The arachidonic acid cascade plays a central role in fungal morphogenesis, yeast-hypha conversion, and biofilm formation.
In C. albicans cells, $\mathrm{PGE}_{2}$ as a virulence factor can regulate fungal growth, colonize, and survive during infection (Noverr and Huffnagle, 2004). $\mathrm{PGE}_{2}$ also plays an important role in promoting the formation of Candida biofilms. Some studies have shown that the less $\mathrm{PGE}_{2}$ production might contribute to the lower level of fungal virulence (Ells et al., 2011). Therefore, an approach to overcome the virulence of $\mathrm{PGE}_{2}$ is sorely needed. A series of enzymes that are involved in the synthesis of $\mathrm{PGE}_{2}$ described above have been studied widely. During in vitro and in vivo studies, COX inhibitors, such as indomethacin, ibuprofen and aspirin, have been confirmed to have antifungal ability by suppressing $C$. albicans $\mathrm{PGE}_{2}$ production and biofilm formation (Liu et al., 2014). The antifungal activity of COX inhibitors is weak in both planktonic and biofilm cells, but in a combined therapy, aspirin can increase fluconazole susceptibly to C. albicans. In addition, the possible antifungal activity of mPGES-1 inhibitors against $C$. albicans was also discussed. As the terminal enzyme downstream of COX-2, mPGES-1 can catalyze the biosynthesis of $\mathrm{PGE}_{2}$ with fewer side effects and, ideally, cannot affect the formation of other housekeeping PGs. Licofelone, as an mPGES-1 inhibitor, has succeeded in reaching the required criteria in phase III clinical trials for treating osteoarthritis. Furthermore, discovery of the possible antifungal ability of mPGES-1 is exceedingly promising. Other factors that influence $\mathrm{PGE}_{2}$ production, such as ROS, NOS, and HOs, are also mentioned in this review.

Hence, further academic research is needed to provide new insights that are able to further our understanding of the importance and role of $\mathrm{PGE}_{2}$ in C. albicans and the mechanism of the potential antifungal agents related to the arachidonic acid cascade, as well as to developing an approach to discover new antifungal drugs for resistant C. albicans.

\section{AUTHOR CONTRIBUTIONS}

XL wrote the review and created the Figure 1, SS, DW, CY, TL, JL helped with it.

\section{ACKNOWLEDGMENTS}

Thanks for the financial support by the Department of Science and Technology of Shandong Province and Shandong Provincial Natural Science Foundation (2013GSF11848, ZR2011HL049, 2015GSF118022).

\section{REFERENCES}

Abdelmegeed, E., and Shaaban, M. I. (2013). Cyclooxygenase inhibitors reduce biofilm formation and yeast-hypha conversion of fluconazole resistant Candida albicans. J. Microbiol. 51, 598-604. doi: 10.1007/s12275-013-3052-6

Abraham, N. G., and Kappas, A. (2008). Pharmacological and clinical aspects of heme oxygenase. Pharmacol. Rev. 60, 79-127. doi: 10.1124/pr.107.07104

Alem, M. A., and Douglas, L. J. (2004). Effects of aspirin and other nonsteroidal anti-inflammatory drugs on biofilms and planktonic cells of Candida albicans. Antimicrob. Agents Chemother. 48, 41-47. doi: 10.1128/AAC.48.1.41-47.2004

Alem, M. A., and Douglas, L. J. (2005). Prostaglandin production during growth of Candida albicans biofilms. J. Med. Microbiol. 54(Pt 11), 1001-1005. doi: 10. 1099/jmm.0.46172-0

Arai, R., Sugita, T., and Nishikawa, A. (2005). Reassessment of the in vitro synergistic effect of fluconazole with the non-steroidal anti-inflammatory agent ibuprofen against Candida albicans. Mycoses 48, 38-41. doi: 10.1111/j.14390507.2004.01052.x

Bauer, J., Koeberle, A., Dehm, F., Pollastro, F., Appendino, G., Northoff, H., et al. (2011). Arzanol, a prenylated heterodimeric phloroglucinyl pyrone, inhibits eicosanoid biosynthesis and exhibits anti-inflammatory 
efficacy in vivo. Biochem. Pharmacol. 81, 259-268. doi: 10.1016/j.bcp.2010. 09.025

Bink, A., Kucharíková, S., Neirinck, B., Vleugels, J., Van Dijck, P., Cammue, B. P., et al. (2012). The nonsteroidal antiinflammatory drug diclofenac potentiates the in vivo activity of caspofungin against Candida albicans biofilms. J. Infect. Dis. 206, 1790-1797. doi: 10.1093/infdis/jis594

Blankenship, J. R., and Mitchell, A. P. (2006). How to build a biofilm: a fungal perspective. Curr. Opin. Microbiol. 9, 588-594. doi: 10.1016/j.mib.2006.10.003

Blumenstein, M., Keelan, J. A., and Mitchell, M. D. (2001). Hypoxia attenuates PGE(2) but increases prostacyclin and thromboxane production in human term villous trophoblast. Placenta 22, 519-525. doi: 10.1053/plac.2001.0689

Bresalier, R. S., Sandler, R. S., Quan, H., Bolognese, J. A., Oxenius, B., Horgan, K., et al. (2005). Cardiovascular events associated with rofecoxib in a colorectal adenoma chemoprevention trial. N. Engl. J. Med. 352, 1092-1102. doi: 10.1056/ NEJMoa050493

Buttgereit, F., Burmester, G. R., and Simon, L. S. (2001). Gastrointestinal toxic side effects of nonsteroidal anti-inflammatory drugs and cyclooxygenase-2-specific inhibitors. Am. J. Med. 110(Suppl. 3A), 13S-9S.

Calderone, R. A., and Fonzi, W. A. (2001). Virulence factors of Candida albicans. Trends Microbiol. 9, 327-335. doi: 10.1016/S0966-842X(01)02094-7

Carrillo-Muñoz, A. J., Giusiano, G., Ezkurra, P. A., and Quindós, G. (2006). Antifungal agents: mode of action in yeast cells. Rev. Esp. Quimioter.19, 130-139.

Chandrasekhar, S., Harvey, A. K., Yu, X. P., Chambers, M. G., Oskins, J. L., Lin, C., et al. (2016). Identification and characterization of novel microsomal prostaglandin E synthase-1 inhibitors for Analgesia. J. Pharmacol. Exp. Ther. 356, 635-644. doi: 10.1124/jpet.115.228932

Chavez-Dozal, A. A., Jahng, M., Rane, H. S., Asare, K., Kulkarny, V. V., Bernardo, S. M., et al. (2014). In vitro analysis of flufenamic acid activity against Candida albicans biofilms. Int. J. Antimicrob. Agents 43, 86-91. doi: 10.1016/ j.ijantimicag.2013.08.018

Clària, J. (2003). Cyclooxygenase-2 biology. Curr. Pharm. Des. 9, 2177-2190. doi: 10.2174/1381612033454054

Costa-de-Oliveira, S., Miranda, I. M., Silva-Dias, A., Silva, A. P., Rodrigues, A. G., and Pina-Vaz, C. (2015). Ibuprofen potentiates the in vivo antifungal activity of fluconazole against Candida albicans murine infection. Antimicrob. Agents Chemother. 59, 4289-4292. doi: 10.1128/AAC.05056-14

Davies, P., Bailey, P. J., Goldenberg, M. M., and Ford-Hutchinson, A. W. (1984). The role of arachidonic acid oxygenation products in pain and inflammation. Annu. Rev. Immunol. 2, 335-357. doi: 10.1146/annurev.iy.02.040184.002003

de Quadros, A. U., Bini, D., Pereira, P. A., Moroni, E. G., and Monteiro, M. C. (2011). Antifungal activity of some cyclooxygenase inhibitors on Candida albicans: PGE2-dependent mechanism. Folia Microbiol. 56, 349-352. doi: 10. 1007/s12223-011-0049-6

Dennis, E. A., Cao, J., Hsu, Y. H., Magrioti, V., and Kokotos, G. (2011). Phospholipase A2 enzymes: physical structure, biological function, disease implication, chemical inhibition, and therapeutic intervention. Chem. Rev. 111, 6130-6185. doi: 10.1021/cr200085w

Desai, P. R., van Wijlick, L., Kurtz, D., Juchimiuk, M., and Ernst, J. F. (2015). Hypoxia and temperature regulated morphogenesis in Candida albicans. PLoS Genet. 11:e1005447. doi: 10.1371/journal.pgen.1005447

Deva, R., Ciccoli, R., Kock, L., and Nigam, S. (2001). Involvement of aspirinsensitive oxylipins in vulvovaginal candidiasis. FEMS Microbiol. Lett. 198, 37-43. doi: 10.1111/j.1574-6968.2001.tb10616.x

Devaux, Y., Seguin, C., Grosjean, S., de Talance, N., Camaeti, V., Burlet, A., et al. (2001). Lipopolysaccharide-induced increase of prostaglandin $\mathrm{E}(2)$ is mediated by inducible nitric oxide synthase activation of the constitutive cyclooxygenase and induction of membrane-associated prostaglandin E synthase. J. Immunol. 167, 3962-3971. doi: 10.4049/jimmunol.167.7.3962

Douglas, L. J. (2003). Candida biofilms and their role in infection. Trends Microbiol. 11, 30-36. doi: 10.1016/S0966-842X(02)00002-1

Ells, R., Kock, J. L., Albertyn, J., Hugo, A., and Pohl, C. H. (2012). Sciadonic acid modulates prostaglandin E2 production by epithelial cells during infection with C. albicans and C. dubliniensis. Prostaglandins Other Lipid Mediat. 97, 66-71. doi: 10.1016/j.prostaglandins.2011.12.001

Ells, R., Kock, J. L., Albertyn, J., Kemp, G., and Pohl, C. H. (2011). Effect of inhibitors of arachidonic acid metabolism on prostaglandin $\mathrm{E}(2)$ production by
Candida albicans and Candida dubliniensis biofilms. Med. Microbiol. Immunol. 200, 23-28. doi: 10.1007/s00430-010-0169-7

Erb-Downward, J. R., and Noverr, M. C. (2007). Characterization of prostaglandin E2 production by Candida albicans. Infect. Immun. 75, 3498-3505. doi: 10. 1128/IAI.00232-07

Evans, J. H., and Leslie, C. C. (2004). The cytosolic phospholipase A2 catalytic domain modulates association and residence time at Golgi membranes. J. Biol. Chem. 279, 6005-6016. doi: 10.1074/jbc.M311246200

Fahmi, H. (2004). mPGES-1 as a novel target for arthritis. Curr. Opin. Rheumatol. 16, 623-627. doi: 10.1097/01.bor.0000129664.81052.8e

Fourie, R., Ells, R., Swart, C. W., Sebolai, O. M., Albertyn, J., and Pohl, C. H. (2016). Candida albicans and Pseudomonas aeruginosa interaction, with focus on the role of eicosanoids. Front. Physiol. 7:64. doi: 10.3389/fphys.2016.00064

Fox, E. P., and Nobile, C. J. (2012). A sticky situation: untangling the transcriptional network controlling biofilm development in Candida albicans. Transcription 3, 315-322. doi: 10.4161/trns.22281

Fox, T., Gotlinger, K. H., Dunn, M. W., Lee, O. L., Milman, T., Zaidman, G., et al. (2013). Dysregulated heme oxygenase-ferritin system in pterygium pathogenesis. Cornea 32, 1276-1282. doi: 10.1097/ICO.0b013e3182936915

García-Sánchez, S., Aubert, S., Iraqui, I., Janbon, G., Ghigo, J. M., and d'Enfert, C. (2004). Candida albicans biofilms: a developmental state associated with specific and stable gene expression patterns. Eukaryot. cell 3, 536-545. doi: 10. 1128/EC.3.2.536-545.2004

Ghalehnoo, Z. R., Rashki, A., Najimi, M., and Dominguez, A. (2010). The role of diclofenac sodium in the dimorphic transition in Candida albicans. Microb. Pathog. 48, 110-115. doi: 10.1016/j.micpath.2009.12.003

Grozer, Z., Toth, A., Toth, R., Kecskemeti, A., Vagvolgyi, C., Nosanchuk, J. D., et al. (2015). Candida parapsilosis produces prostaglandins from exogenous arachidonic acid and OLE2 is not required for their synthesis. Virulence 6, 85-92. doi: 10.4161/21505594.2014.988097

Guillemot, L., Medina, M., Pernet, E., Leduc, D., Chignard, M., Touqui, L., et al. (2014). Cytosolic phospholipase A2alpha enhances mouse mortality induced by Pseudomonas aeruginosa pulmonary infection via interleukin 6. Biochimie 107(Pt A), 95-104. doi: 10.1016/j.biochi.2014.08.018

He, C., Wu, Y., Lai, Y., Cai, Z., Liu, Y., and Lai, L. (2012). Dynamic eicosanoid responses upon different inhibitor and combination treatments on the arachidonic acid metabolic network. Mol. Biosyst. 8, 1585-1594. doi: 10.1039/ c2mb05503a

Hegen, M., Sun, L., Uozumi, N., Kume, K., Goad, M. E., Nickerson-Nutter, C. L., et al. (2003). Cytosolic phospholipase A2alpha-deficient mice are resistant to collagen-induced arthritis. J. Exp. Med. 197, 1297-1302. doi: 10.1084/jem. 20030016

Iyer, J. P., Srivastava, P. K., Dev, R., Dastidar, S. G., and Ray, A. (2009). Prostaglandin E(2) synthase inhibition as a therapeutic target. Expert Opin. Ther. Targets 13, 849-865. doi: 10.1517/14728220903018932

Kalo-Klein, A., and Witkin, S. S. (1990). Prostaglandin E2 enhances and gamma interferon inhibits germ tube formation in Candida albicans. Infect. Immun. 58, 260-262.

Khan, M., Shunmugavel, A., Dhammu, T. S., Matsuda, F., Singh, A. K., and Singh, I. (2015). Oral administration of cytosolic PLA2 inhibitor arachidonyl trifluoromethyl ketone ameliorates cauda equina compression injury in rats. J. Neuroinflammation 12:94. doi: 10.1186/s12974-015-0311-y

Koeberle, A., Northoff, H., and Werz, O. (2009b). Curcumin blocks prostaglandin E2 biosynthesis through direct inhibition of the microsomal prostaglandin E2 synthase-1. Mol. Cancer Ther. 8, 2348-2355. doi: 10.1158/1535-7163.MCT-090290

Koeberle, A., Pollastro, F., Northoff, H., and Werz, O. (2009a). Myrtucommulone, a natural acylphloroglucinol, inhibits microsomal prostaglandin E(2) synthase1. Br. J. Pharmacol. 156, 952-961. doi: 10.1111/j.1476-5381.2009.00070.x

Koeberle, A., Rossi, A., Zettl, H., Pergola, C., Dehm, F., Bauer, J., et al. (2010). The molecular pharmacology and in vivo activity of 2-(4-chloro-6(2,3-dimethylphenylamino)pyrimidin-2-ylthio)octanoic acid (YS121), a dual inhibitor of microsomal prostaglandin E2 synthase-1 and 5-lipoxygenase. J. Pharmacol. Exp. Ther. 332, 840-848. doi: 10.1124/jpet.109.160663

Korbecki, J., Baranowska-Bosiacka, I., Gutowska, I., and Chlubek, D. (2013). The effect of reactive oxygen species on the synthesis of prostanoids from arachidonic acid. J. Physiol. Pharmacol. 64, 409-421. 
Korotkova, M., and Jakobsson, P. J. (2014). Characterization of microsomal prostaglandin E synthase 1 inhibitors. Basic Clin. Pharmacol. Toxicol. 114, 64-69. doi: 10.1111/bcpt.12162

Krause, J., Geginat, G., and Tammer, I. (2015). Prostaglandin E2 from Candida albicans stimulates the growth of Staphylococcus aureus in mixed biofilms. PLoS ONE 10:e0135404. doi: 10.1371/journal.pone.0135404

Kulkarni, S. K., and Singh, V. P. (2007). Licofelone-a novel analgesic and anti-inflammatory agent. Curr. Top. Med. Chem. 7, 251-263. doi: 10.2174/ 156802607779941305

Levitin, A., and Whiteway, M. (2007). The effect of prostaglandin E2 on transcriptional responses of Candida albicans. Microbiol. Res. 162, 201-210. doi: 10.1016/j.micres.2007.02.001

Li, X., Hou, Y., Yue, L., Liu, S., Du, J., and Sun, S. (2015). Potential targets for antifungal drug discovery based on growth and virulence in Candida albicans. Antimicrob. Agents Chemother. 59, 5885-5891. doi: 10.1128/AAC.00 $726-15$

Liu, S., Hou, Y., Chen, X., Gao, Y., Li, H., and Sun, S. (2014). Combination of fluconazole with non-antifungal agents: a promising approach to cope with resistant Candida albicans infections and insight into new antifungal agent discovery. Int. J. Antimicrob. Agents 43, 395-402. doi: 10.1016/j.ijantimicag. 2013.12.009

Lu, Y., Su, C., Solis, N. V., Filler, S. G., and Liu, H. (2013). Synergistic regulation of hyphal elongation by hypoxia, $\mathrm{CO}(2)$, and nutrient conditions controls the virulence of Candida albicans. Cell Host Microbe 14, 499-509. doi: 10.1016/j. chom.2013.10.008

Marnett, L. J., Wright, T. L., Crews, B. C., Tannenbaum, S. R., and Morrow, J. D. (2000). Regulation of prostaglandin biosynthesis by nitric oxide is revealed by targeted deletion of inducible nitric-oxide synthase. J. Biol. Chem. 275, 13427-13430. doi: 10.1074/jbc.275.18.13427

Martel-Pelletier, J., Lajeunesse, D., Reboul, P., and Pelletier, J. P. (2003). Therapeutic role of dual inhibitors of 5-LOX and COX, selective and nonselective non-steroidal anti-inflammatory drugs. Ann. Rheum. Dis. 62, 501-509. doi: 10.1136/ard.62.6.501

Meirer, K., Steinhilber, D., and Proschak, E. (2014). Inhibitors of the arachidonic acid cascade: interfering with multiple pathways. Basic Clin. Pharmacol. Toxicol. 114, 83-91. doi: 10.1111/bcpt.12134

Mishra, N. N., Ali, S., and Shukla, P. K. (2014). Arachidonic acid affects biofilm formation and PGE2 level in Candida albicans and non-albicans species in presence of subinhibitory concentration of fluconazole and terbinafine. Braz. J. Infect. Dis. 18, 287-293. doi: 10.1016/j.bjid.2013.09.006

Morato-Marques, M., Campos, M. R., Kane, S., Rangel, A. P., Lewis, C., Ballinger, M. N., et al. (2011). Leukotrienes target F-actin/cofilin-1 to enhance alveolar macrophage anti-fungal activity. J. Biol. Chem. 286, 28902-28913. doi: 10.1074/ jbc.M111.235309

Murakami, M., Nakashima, K., Kamei, D., Masuda, S., Ishikawa, Y., Ishii, T., et al. (2003). Cellular prostaglandin E2 production by membrane-bound prostaglandin E synthase-2 via both cyclooxygenases-1 and -2. J. Biol. Chem. 278, 37937-37947. doi: 10.1074/jbc.M305108200

Murakami, M., Nakatani, Y., Tanioka, T., and Kudo, I. (2002). Prostaglandin E synthase. Prostaglandins Other Lipid Mediat. 68-69, 383-399. doi: 10.1016/ S0090-6980(02)00043-6

Nash, E. E., Peters, B. M., Fidel, P. L., and Noverr, M. C. (2016). Morphologyindependent virulence of candida species during polymicrobial intraabdominal infections with Staphylococcus aureus. Infect. Immun. 84, 90-98. doi: 10.1128/IAI.01059-15

Nobile, C. J., and Johnson, A. D. (2015). Candida albicans biofilms and human disease. Ann. Rev. Microbiol. 69, 71-92. doi: 10.1146/annurev-micro-091014104330

Noverr, M. C., and Huffnagle, G. B. (2004). Regulation of Candida albicans morphogenesis by fatty acid metabolites. Infect. Immun. 72, 6206-6210. doi: 10. 1128/IAI.72.11.6206-6210.2004

Noverr, M. C., Erb-Downward, J. R., and Huffnagle, G. B. (2003). Production of eicosanoids and other oxylipins by pathogenic eukaryotic microbes. Clin. Microbiol. Rev. 16, 517-533. doi: 10.1128/CMR.16.3.517-533.2003

Noverr, M. C., Phare, S. M., Toews, G. B., Coffey, M. J., and Huffnagle, G. B. (2001). Pathogenic yeasts Cryptococcus neoformans and Candida albicans produce immunomodulatory prostaglandins. Infect. Immun. 69, 2957-2963. doi: 10.1128/IAI.69.5.2957-2963.2001
Noverr, M. C., Toews, G. B., and Huffnagle, G. B. (2002). Production of prostaglandins and leukotrienes by pathogenic fungi. Infect. Immun. 70, 400-402. doi: 10.1128/IAI.70.1.400-402.2002

Park, J. H., Park, E. B., Lee, J. Y., and Min, J. Y. (2016). Identification of novel membrane-associated prostaglandin E synthase-1 (mPGES-1) inhibitors with anti-influenza activities in vitro. Biochem. Biophys. Res. Commun. 469, 848-855. doi: 10.1016/j.bbrc.2015.11.129

Park, J. Y., Pillinger, M. H., and Abramson, S. B. (2006). Prostaglandin E2 synthesis and secretion: the role of PGE2 synthases. Clin. Immunol. 119, 229-240. doi: 10. 1016/j.clim.2006.01.016

Parti, R. P., Loper, R., Brown, G. D., Gordon, S., Taylor, P. R., Bonventre, J. V., et al. (2010). Cytosolic phospholipase a2 activation by Candida albicans in alveolar macrophages: role of dectin-1. Am. J. Respir. Cell Mol. Biol. 42, 415-423. doi: 10. 1165/rcmb.2009-0110OC

Payandemehr, B., Khoshneviszadeh, M., Varastehmoradi, B., Gholizadeh, R., Bahremand, T., Attar, H., et al. (2015). A COX/5-LOX inhibitor licofelone revealed anticonvulsant properties through inos diminution in mice. Neurochem. Res. 40, 1819-1828. doi: 10.1007/s11064-015-1669-z

Peters-Golden, M., and Henderson, W. R. Jr. (2007). Leukotrienes. N. Engl. J. Med. 357, 1841-1854. doi: 10.1056/NEJMra071371

Pina-Vaz, C., Sansonetty, F., Rodrigues, A. G., Martinez-De-Oliveira, J., Fonseca, A. F., and Mårdh, P. A. (2000). Antifungal activity of ibuprofen alone and in combination with fluconazole against Candida species. J. Med. Microbiol. 49, 831-840. doi: 10.1099/0022-1317-49-9-831

Rådmark, O., and Samuelsson, B. (2010). Microsomal prostaglandin E synthase-1 and 5-lipoxygenase: potential drug targets in cancer. J. Intern. Med. 268, 5-14. doi: $10.1111 / j .1365-2796.2010 .02246 . x$

Rainsford, K. D. (2007). Anti-inflammatory drugs in the 21st century. Sub Cell. Biochem. 42, 3-27. doi: 10.1007/1-4020-5688-5_1

Ricardo, E., Costa-de-Oliveira, S., Dias, A. S., Guerra, J., Rodrigues, A. G., and Pina-Vaz, C. (2009). Ibuprofen reverts antifungal resistance on Candida albicans showing overexpression of CDR genes. FEMS Yeast Res. 9, 618-625. doi: 10.1111/j.1567-1364.2009.00504.x

Romani, L., and Kaufmann, S. H. (1998). Immunity to fungi: editorial overview. Res. Immunol. 149, 277-281. doi: 10.1016/S0923-2494(98)80751-7

Rosato, A., Catalano, A., Carocci, A., Carrieri, A., Carone, A., Caggiano, G., et al. (2016). In vitro interactions between anidulafungin and nonsteroidal anti-inflammatory drugs on biofilms of Candida spp. Bioorg. Med. Chem. 24, 1002-1005. doi: 10.1016/j.bmc.2016.01.026

Rossi, A., Pergola, C., Koeberle, A., Hoffmann, M., Dehm, F., Bramanti, P., et al. (2010). The 5-lipoxygenase inhibitor, zileuton, suppresses prostaglandin biosynthesis by inhibition of arachidonic acid release in macrophages. $\mathrm{Br}$. J. Pharmacol. 161, 555-570. doi: 10.1111/j.1476-5381.2010.00930.x

Rotondo, S., Dell'Elba, G., Krauze-Brzósko, K., Manarini, S., Martelli, N., Pecce, R., et al. (2002). Licofelone, a dual lipoxygenase-cyclooxygenase inhibitor, downregulates polymorphonuclear leukocyte and platelet function. Eur. J. Pharmacol. 453, 131-139. doi: 10.1016/S0014-2999(02)02385-3

Rusu, E., Radu-Popescu, M., Pelinescu, D., and Vassu, T. (2014). Treatment with some anti-inflammatory drugs reduces germ tube formation in Candida albicans strains. Braz. J. Microbiol. 45, 1379-1383. doi: 10.1590/S151783822014000400031

Saha, S., Engström, L., Mackerlova, L., Jakobsson, P. J., and Blomqvist, A. (2005). Impaired febrile responses to immune challenge in mice deficient in microsomal prostaglandin E synthase-1. Am. J. Physiol. Regul. Integr. Comp. Physiol. 288, R1100-R1107. doi: 10.1152/ajpregu.00872.2004

Scott, E. M., Tariq, V. N., and McCrory, R. M. (1995). Demonstration of synergy with fluconazole and either ibuprofen, sodium salicylate, or propylparaben against Candida albicans in vitro. Antimicrob. Agents Chemother. 39, 2610-2614. doi: 10.1128/AAC.39.12.2610

Shibata, Y., Henriksen, R. A., Honda, I., Nakamura, R. M., and Myrvik, Q. N. (2005). Splenic PGE2-releasing macrophages regulate Th1 and Th2 immune responses in mice treated with heat-killed BCG. J. Leukoc. Biol. 78, 1281-1290. doi: $10.1189 / \mathrm{jlb} .0605321$

Shrestha, S. K., Fosso, M. Y., and Garneau-Tsodikova, S. (2015). A combination approach to treating fungal infections. Sci. Rep. 5:17070. doi: 10.1038/srep17070

Sievert, D. M., Ricks, P., Edwards, J. R., Schneider, A., Patel, J., Srinivasan, A., et al. (2013). Antimicrobial-resistant pathogens associated with healthcareassociated infections: summary of data reported to the National Healthcare 
Safety Network at the Centers for Disease Control and Prevention, 2009-2010. Infect. Control Hosp. Epidemiol. 34, 1-14. doi: 10.1086/668770

Silva, S., Negri, M., Henriques, M., Oliveira, R., Williams, D. W., and Azeredo, J. (2012). Candida glabrata, Candida parapsilosis and Candida tropicalis: biology, epidemiology, pathogenicity and antifungal resistance. FEMS Microbiol. Rev. 36, 288-305. doi: 10.1111/j.1574-6976.2011.00278.x

Spector, A. A. (2009). Arachidonic acid cytochrome P450 epoxygenase pathway. J. Lipid Res. 50(Suppl.), S52-S56. doi: 10.1194/jlr.R800038-JLR200

Sugimoto, Y., Narumiya, S., and Ichikawa, A. (2000). Distribution and function of prostanoid receptors: studies from knockout mice. Prog. Lipid Res. 39, 289-314. doi: 10.1016/S0163-7827(00)00008-4

Sun, S. X., Lee, K. Y., Bertram, C. T., and Goldstein, J. L. (2007). Withdrawal of COX-2 selective inhibitors rofecoxib and valdecoxib: impact on NSAID and gastroprotective drug prescribing and utilization. Curr. Med. Res. Opin. 23, 1859-1866. doi: 10.1185/030079907X210561

Suram, S., Brown, G. D., Ghosh, M., Gordon, S., Loper, R., Taylor, P. R., et al. (2006). Regulation of cytosolic phospholipase A2 activation and cyclooxygenase 2 expression in macrophages by the beta-glucan receptor. $J$. Biol. Chem. 281, 5506-5514. doi: 10.1074/jbc.M509824200

Suram, S., Gangelhoff, T. A., Taylor, P. R., Rosas, M., Brown, G. D., Bonventre, J. V., et al. (2010). Pathways regulating cytosolic phospholipase A2 activation and eicosanoid production in macrophages by Candida albicans. J. Biol. Chem. 285, 30676-30685. doi: 10.1074/jbc.M110.143800

Tanioka, T., Nakatani, Y., Kobayashi, T., Tsujimoto, M., Oh-ishi, S., Murakami, M., et al. (2003). Regulation of cytosolic prostaglandin E2 synthase by $90-\mathrm{kDa}$ heat shock protein. Biochem. Biophys. Res. Commun. 303, 1018-1023. doi: 10.1016/ S0006-291X(03)00470-4

Trebino, C. E., Stock, J. L., Gibbons, C. P., Naiman, B. M., Wachtmann, T. S., Umland, J. P., et al. (2003). Impaired inflammatory and pain responses in mice lacking an inducible prostaglandin E synthase. Proc. Natl. Acad. Sci. U.S.A. 100, 9044-9049. doi: 10.1073/pnas.1332766100

Uematsu, S., Matsumoto, M., Takeda, K., and Akira, S. (2002). Lipopolysaccharidedependent prostaglandin $\mathrm{E}(2)$ production is regulated by the glutathionedependent prostaglandin $\mathrm{E}(2)$ synthase gene induced by the Toll-like receptor 4/MyD88/NF-IL6 pathway. J. Immunol. 168, 5811-5816. doi: 10.4049/ jimmunol.168.11.5811

Vidal, C., Gómez-Hernández, A., Sánchez-Galán, E., Gonzalez, A., Ortega, L., Gómez-Gerique, J. A., et al. (2007). Licofelone, a balanced inhibitor of cyclooxygenase and 5-lipoxygenase, reduces inflammation in a rabbit model of atherosclerosis. J. Pharmacol. Exp. Ther. 320, 108-116. doi: 10.1124/jpet.106. 110361
Wang, D., and Dubois, R. N. (2010). Eicosanoids and cancer. Nat. Rev. Cancer 10, 181-193. doi: $10.1038 / \mathrm{nrc} 2809$

Wang, S. H., Wang, S. C., Chen, P. C., Wang, S. T., and Liu, Y. W. (2016). Induction of cyclooxygenase-2 gene by Candida albicans through EGFR, ERK, and p38 pathways in human urinary epithelium. Med. Mycol. doi: 10.1093/ mmy/myw082. [Epub ahead of print].

Werz, O., and Steinhilber, D. (2006). Therapeutic options for 5-lipoxygenase inhibitors. Pharmacol. Ther. 112, 701-718. doi: 10.1016/j.pharmthera.2006. 05.009

Yang, S., Liao, Y., Cong, L., Lu, X., and Yang, R. (2016). In Vitro interactions between non-steroidal anti-inflammatory drugs and antifungal agents against planktonic and biofilm forms of Trichosporon asahii. PLoS ONE 11:e0157047. doi: 10.1371/journal.pone.0157047

Yuan, C., and Smith, W. L. (2015). A cyclooxygenase-2-dependent prostaglandin E2 biosynthetic system in the Golgi apparatus. J. Biol. Chem. 290, 5606-5620. doi: $10.1074 / j b c . M 114.632463$

Yücesoy, M., Oktem, I. M., and Gülay, Z. (2000). In-vitro synergistic effect of fluconazole with nonsteroidal anti-inflammatory agents against Candida albicans strains. J. Chemother. 12, 385-389. doi: 10.1179/joc.2000.12. 5.385

Yun, B., Lee, H., Jayaraja, S., Suram, S., Murphy, R. C., and Leslie, C. C. (2016). Prostaglandins from cytosolic phospholipase A2alpha/cyclooxygenase1 pathway and mitogen-activated protein kinases regulate gene expression in Candida albicans-infected macrophages. J. Biol. Chem. 291, 7070-7086. doi: 10. 1074/jbc.M116.714873

Zhou, Y., Wang, G., Li, Y., Liu, Y., Song, Y., Zheng, W., et al. (2012). In vitro interactions between aspirin and amphotericin B against planktonic cells and biofilm cells of Candida albicans and C. parapsilosis. Antimicrob. Agents Chemother. 56, 3250-3260. doi: 10.1128/AAC.06 082-11

Conflict of Interest Statement: The authors declare that the research was conducted in the absence of any commercial or financial relationships that could be construed as a potential conflict of interest.

Copyright $\odot 2016 \mathrm{Liu}$, Wang, Yu, Li, Liu and Sun. This is an open-access article distributed under the terms of the Creative Commons Attribution License (CC BY). The use, distribution or reproduction in other forums is permitted, provided the original author(s) or licensor are credited and that the original publication in this journal is cited, in accordance with accepted academic practice. No use, distribution or reproduction is permitted which does not comply with these terms. 